\title{
Comunicação
}

[Communication]

\section{Leveduras no rúmen de caprinos e bovinos de corte criados em pastagem tropicais}

[Yeasts in the rumen of beef steers and goats raised on tropical pasture]

\author{
F.O. Abrão ${ }^{1}$, C.E.S. Freitas ${ }^{3}$, E.R. Duarte ${ }^{2 *}$, L.C. Geraseev ${ }^{2}$, S.M.P. Barreto ${ }^{1}$, \\ A.O. Medeiros ${ }^{4}$, C.A. Rosa ${ }^{4}$ \\ ${ }^{1}$ Aluno de pós-graduação - ICA - UFMG - Montes Claros, MG \\ ${ }^{2}$ Instituto de Ciências Agrárias - ICA-UFMG \\ Avenida Universitária, 1000 \\ 39404-006 - Montes Claros, MG \\ ${ }^{3}$ Aluno de graduação - ICA-UFMG - Montes Claros, MG \\ ${ }^{4}$ Instituto de Ciências Biológicas - ICB-UFMG - Belo Horizonte, MG
}

Em diferentes países em todo o mundo, tem-se caracterizado a microbiota ruminal e registrado a importante participação dos fungos na digestão e no equilíbrio do ecossistema ruminal e na saúde dos ruminantes. Entretanto, pouco se tem estudado sobre a caracterização e participação de fungos aeróbios em animais criados em condições extensivas, pastagens de baixo valor nutricional, frequentemente lignificadas. Pesquisas relacionadas ao ambiente ruminal de animais nessas circunstâncias permitiriam a seleção de isolados fúngicos com atividade superior de enzimas celulolíticas e xilanolíticas, importantes na degradação da parede celular vegetal.

Culturas microbianas vivas dos fungos aeróbios Aspergillus orizae e Sacchariomyces cerevisae e de seus respectivos extratos têm sido utilizadas como suplementos alimentares para ruminantes em escala comercial, com evidentes resultados positivos. Alguns estudos têm demonstrado que esses aditivos microbianos podem melhorar a produtividade de ruminantes em cerca de 7 a $8 \%$ (Martin e Nisbet, 1992; Wallace, 1994). Um recente estudo descreveu os feitos da administração de Saccharomyces cerevisiae na dieta de cabras leiteiras. Nele foi observado aumento significativo na produção e redução significativa de unidades formadoras de colônias de Escherichia coli, juntamente com aumento de Lactobacillus spp. nas fezes dos animais tratados

Recebido em 17 de março de 2010

Aceito em 21 de março de 2011

*Autor para correspondência (corresponding author)

Email: duartevet@nca.ufmg.br com a levedura, indicando melhor estabilidade do ecossistema intestinal (Stella et al., 2007).

Apesar da literatura científica registrar o benefício da inclusão de leveduras e fungos na dieta dos ruminantes, poucos estudos têm descrito o isolamento e a quantificação de leveduras e fungos naturalmente presentes no rúmen e sua importância na saúde e nutrição dos animais. Dessa forma, neste trabalho o objetivo principal foi avaliar as características físicoquímicas do suco do rúmen e analisar a micobiota aeróbia ruminal de caprinos e bovinos de corte criados em pastagens tropicais.

A amostragem desse estudo foi constituída por 18 caprinos mestiços machos, sem raça definida, com 18 a 22 meses de idade, e por 31 novilhos mestiços Nelore, com 20 a 40 meses de idade. Todos os animais eram provenientes da zona rural do município de Montes Claros, norte de Minas Gerais, e foram criados em pastagens de Brachiaria decumbens e B. mutica. Os animais recebiam mistura mineral adequada a cada categoria e água ad libitum. Nesta região, localizada a $16^{\circ} 51^{\prime} 38^{\prime \prime} d e$ latitude e $44^{\circ} 55^{\prime} 00^{\prime \prime}$ de longitude, a temperatura média anual é de $24,2^{\circ} \mathrm{C}$, o clima é quente e seco, com um período de estiagem de abril a outubro. As coletas do fluido ruminal concentraram-se no período de seca da região, correspondendo ao final de março até o início de novembro de 2007, quando as pastagens encontravam-se mais lignificadas. 
As amostras do líquido ruminal dos novilhos foram obtidas em abatedouro com inspeção municipal do Distrito de Montes Claros. Após jejum de 12 a 18 horas, os animais foram abatidos por concussão cerebral e sangria. As amostras foram obtidas imediatamente ao abate, após a incisão do saco ventral do rúmen e coleta de aproximadamente $10 \mathrm{~mL}$ de fluido, com auxílio de pipetas estéreis. Nos caprinos, após jejum prévio de 12 horas, a coleta foi realizada no momento da implantação cirúrgica de fístulas ruminais para futuros experimentos de digestibilidade. Os procedimentos adotados estiveram de acordo com o Comitê de Ética em Experimentação Animal da Universidade Federal de Minas Gerais (protocolo 156/2005). Foram coletados aproximadamente $15 \mathrm{~mL}$ de fluido ruminal, com auxílio de pipetas estéreis, diretamente do saco ventral do rúmen. As amostras foram transportadas em caixas isotérmicas e armazenadas por, no máximo, uma hora, em tubos de ensaio vedados e estéreis.

A análise macroscópica do líquido coletado foi realizada imediatamente após a coleta, em um tubo contendo $8 \mathrm{~mL}$ do suco amostrado. Foram avaliados cor, odor, viscosidade e tempo de redução do azul de metileno na concentração 0,03\%. O pH foi estimado utilizando-se um potenciômetro digital (Dirksen, 1993).

Para cultivo, quantificação, isolamento e identificação dos fungos aeróbios, foram preparadas diferentes diluições decimais sucessivas do líquido do ruminal em tubos que continham 9mL de solução salina estéril. Após cada diluição, os tubos foram homogeneizados durante três minutos, e alíquotas de 100 microlitros das diluições $10^{1}$ a $10^{6}$ foram inoculadas em placas estéreis contendo o meio ágar Sabouraud, acrescido de clorafenicol (concentração final de $250 \mathrm{mg} / \mathrm{L}$ ). Os inóculos foram homogeneizados com alças de Drigalski estéreis, e as placas foram incubadas em estufa BOD a $37^{\circ} \mathrm{C}$ e monitoradas para o crescimento de colônias fúngicas por até 21 dias (Kurtzman e Fell, 1998; Lacaz et al., 2002).

Foram reisoladas 30 amostras de leveduras provenientes de caprinos em tubos contendo o mesmo meio, sendo recolhidas até três colônias distintas de cada animal. As provas taxonômicas utilizadas para identificação das leveduras consistiram de análises micromorfológicas, fisiológicas e bioquímicas, com avaliação da capacidade fermentativa, produção de urease e assimilação de fontes de carbono (glicose, galactose, L-sorbose, maltose, sacarose, celobiose, trealose, lactose, melibiose, rafinose, melezitose, inulina, amido solúvel, D-xilose, Larabinose, D-arabinose, D-ribose, L-ramnose, etanol, glicerol, eritritol, adonitol, galactitol, Dmanitol, D-glucitol, salicina, citrato, m-inositol, metanol, hexadecano, xylitol, gluconato, Nacetilglucosamina e glicosamina) (Kurtzman e Fell, 1998).

Para análise dos dados quantificados, as médias foram comparadas pelo teste $t$, com nível de significância de 5\%. As taxas de positividades entre os diferentes tipos de fungos encontrados foram avaliadas utilizando-se o teste do quiquadrado, considerando-se os valores de $\mathrm{P}<0,05$ (Sampaio, 1998).

As amostras apresentaram-se verdes, com viscosidade levemente espessa e odor aromático. Segundo Dirksen (1993), o suco ruminal com essas características apresentaria uma microbiota levemente ativa.

A redução do azul de metileno apresentou variações de dois a cinco minutos nos caprinos e de sete a 32 minutos nos bovinos. Como as duas espécies de ruminantes avaliadas recebiam dietas semelhantes, essa diferença no tempo de redução do azul de metileno poderia ser justificada pelo maior tempo de jejum em que os bovinos se encontravam, o que proporcionou redução na concentração das enzimas redutoras. Estudos mostram que a dieta fornecida para os animais influencia diretamente na redução do azul de metileno.

Segundo Dirksen (1993), uma dieta com elevada proporção de concentrado provoca redução de apenas um minuto, e uma dieta constituída exclusivamente de feno pode levar à redução de três a seis minutos. O tempo de redução do azul de metileno prolonga-se para até mais de 15 minutos na inatividade simples da microbiota em animais alimentados com dietas pobres em energia e proteína ou com inapetência prolongada (Dirksen, 1993).

Quanto ao pH, não houve diferença significativa entre os grupos amostrados. Os caprinos apresentaram média de $\mathrm{pH}$ de $6,86 \pm 0,73$, e os 
bovinos de 7,69 $\pm 0,17$. Essas médias, nas duas espécies avaliadas, estão dentro ou próximas dos valores normais, segundo Dirksen (1993). O ponto ótimo da digestão da fibra é dado quando valores de $\mathrm{pH}$ se encontram entre 6,7 e 7,1. Em situações em que o pH atinge valores abaixo de 6,2 , ocorre redução na digestibilidade da fibra, pois os microrganismos celulolíticos são sensíveis a baixos valores de pH (Orskov, 1988).

No cultivo, foi observado crescimento de leveduras em todas as amostras provenientes dos caprinos, em uma concentração média de $3,2 \times 10^{5}$ unidades formadoras de colônias (UFC) por $\mathrm{mL}$ de suco amostrado. Diferentemente, nas amostras dos novilhos, não foi observado o crescimento de leveduras para nenhum dos cultivos. Fungos micelianos aeróbios estavam ausentes no cultivo do líquido ruminal para as duas espécies estudadas.

Até o presente momento, não se sabe o motivo da variação entre a microbiota fúngica de caprinos e novilhos, já que ambos receberam dietas semelhantes, a coleta do suco do rúmen foi realizada no mesmo período do ano e os animais originaram-se de propriedades rurais de Montes Claros. Esses resultados sugerem que o fator espécie animal atuaria no favorecimento ou na inibição de fungos aeróbios no rúmen, e isso poderia estar associado ao hábito alimentar mais seletivo dos caprinos.

A identificação dos 30 isolados de leveduras provenientes do rúmen caprino indicou que a maior frequência, 90\%, foi da Pichia (P.) membranifaciens, presente em todos os animais avaliados, seguida de Candida tropicalis, 10\%, presente em apenas três animais. Todas as amostras de $P$. membranifaciens apresentaram capacidade de utilização de etanol, e isso poderia indicar um possível efeito benéfico, por reduzir perdas no processo de fermentação ruminal. A levedura, após crescer e utilizar esse substrato, poderia compor parte da proteína microbiana ruminal e ser utilizada pelo hospedeiro.

Até o momento, não foram encontrados relatos na literatura científica quanto à presença de $P$. membranifaciens no rúmen de animais. Segundo Santos et al. (2000), P. membranifaciens é naturalmente encontrada na pele da uva e apresenta uma toxina killer que tem ação contra o Botrytis cinérea, fungo fitopatógeno de videiras. Pesquisas in vitro realizadas por esses autores confirmaram que a levedura poderia ser utilizada no controle biológico do fungo.

O papel da espécie $P$. membranifaciens no rúmen ainda é desconhecido, e os efeitos da presença dominante sobre outros fungos e leveduras aeróbias estão para ser elucidados. Um dos fatores para justificar o predomínio dessa espécie no rúmen dos caprinos seria a produção de toxinas killers, como descrito anteriormente. Estudos devem avaliar a participação dessa levedura na microbiota autóctone ruminal de caprinos, considerando-se um possível potencial probiótico ou patogênico oportunista no ecossistema ruminal. Recentes estudos indicam que essa toxina killer tem atividade reduzida em $\mathrm{pH}$ abaixo de 6 e efeito fungicida contra determinados fungos, entretanto já foi constatada a inatividade contra a espécie Saccharomyces cerevisiae (Santos et al., 2009) .

A espécie Candida tropicalis tem sido relatada na literatura como prevalente em quadros patogênicos em humanos imunocomprometidos (Lima et al., 2008). Com isso, evidencia-se ainda a importância desses microrganismos em casos de saúde pública. Em bovinos, da raça Gir, essa espécie já foi associada à otite parasitária (Duarte et al., 2001). A prevalência dessa levedura em ruminantes também é pouco conhecida na literatura científica de interesse veterinário e zootécnico, requerendo, assim, mais estudos.

Com esses dados, pode-se concluir que a micobiota ruminal aeróbia de caprinos e de novilhos de corte apresentou diferenças em sua constituição. A espécie $P$. membranifaciens é descrita pela primeira vez no ambiente ruminal de caprinos e em prevalência e concentrações significativas, destacando-se sua importância na digestão e saúde dos ruminantes, pois poderá elucidar a ecologia desses microrganismos no ambiente ruminal. Pesquisas dessa natureza poderiam, ainda, indicar isolados com atividade de enzimas relevantes na fermentação ruminal e com antibiose para microrganismos patogênicos.

Palavras-chave: ruminantes, fermentação, fungo anaeróbio, período seco 


\begin{abstract}
Yeasts suplemented in the rumen have been produced benefic interations in the digestion and in the health of the ruminants. This study aimed to quantify, to isolate and, to identify aerobic fungi and yeasts naturally present in the rumen of goats and cattle raised on tropical pastures of the North of Minas Gerais State, Brazil. Samples of 15mL of ruminal juice from 18 hibrid goats and 31 crossbred Nellore steers were used. The physico-chemical characteristics of the samples were evaluated and mycological culture, quantification, and identification of the aerobic fungi were performed. The results indicated the absence of yeasts in the ruminal fluid of steers. However, theses microorganisms were cultured from ruminal juice for all evaluated goats, at an average concentration of $3.2 \times 10^{5} \mathrm{CFU} / \mathrm{mL}$. The species Pichia membranifaciens was the most frequently identified yeast, suggesting its participation in the ruminal microbiot of theses small ruminants.
\end{abstract}

Keywords: ruminants, fermentation, aerobic fungi, dry period

\section{AGRADECIMENTOS}

Os autores agradecem ao apoio financeiro do Conselho Nacional de Desenvolvimento Científico e Tecnológico (CNPq), da Fundação de Amparo a Pesquisa do Estado de Minas Gerais (FAPEMIG) e do Fundo de Desenvolvimento Científico e Tecnológico do Banco do Nordeste (FUNDECI).

\section{REFERÊNCIAS BIBLIOGRÁFICAS}

DIRKSEN, G. Sistema digestivo. In: DIRKSEN, G.; GRÜNDER, H. D.; STÖBER, M. (Eds.). Rosenberger: Exame clínico dos bovinos. Rio de Janeiro: Guanabara-Koogan, 1993. p.167-169.

DUARTE, E.R.; RESENDE, J.C.P.; ROSA, C.A. et al. Prevalence of yeast and mycelial fungi in bovine parasitic otitis in the state of Minas Gerais, Brazil. J. Vet. Med., v.48, p.631-635, 2001.

KURTZMAN, C.P.; FELL, J.W.: The yeast: a taxonomic study. 4.ed. Amsterdam: Elsevier, 1998. , p.1055.

LACAZ, C.S.; PORTO, E.; MARTINS, J.E.C. et al. Tratado de micologia médica. 9. ed. São Paulo: Savier, 2002. p.1120.

LIMA, K.M.; DELGADO, M.; REGO, R.S.M. et al. Candida albicans e Candida tropicalis. Isoladas de onicomicose em pacientes HIVpositivos: corresistência in vitro dos azólicos. Rev. Patol. Trop., v.37, p.57-64, 2008.
MARTIN, A.S.; NISBET, D.J. Effect of directfeed microbial on rumen microbial fermentation . J. Dairy Sci., v.75, p.1736-1744, 1992.

ORSKOV, E.R. Nutricion proteica de los ruminantes. Saragoza: Acribia, 1988. p.178.

SAMPAIO, I.B.M. Estatística aplicada à experimentação animal. 2.ed. Belo Horizonte: Fundação de Ensino e Pesquisa em Medicina Veterinária e Zootecnia, 1998. p.263.

SANTOS, A.; MARQUINA, D.; LEAL, J.A. et al. $(1 \rightarrow 6)-\beta$-D-glucan as cell wall receptor for Pichia membranifaciens killer toxin. Cat. Inist., v. 66, p.1809-813, 2000.

SANTOS, A.; SAN MAURO, M.; BRAVO, E. et al. PMKT2, a new killer toxin from Pichia membranifaciens, and its promising biotechnological properties for control of the spoilage yeast Brettanomyces bruxellensis. Microbiology, v. 156, p.624-634, 2009.

STELLA, A.V.; PARATTE, R.; VALNEGRI, L. et al. Effect of administration of live Saccharomyces cerevisiae on milk production, milk composition, blood metabolites, and faecal flora in early lactating dairy goats. Small Ruminant Res., v. p.7-13, 2007.

WALLACE, R.J. Ruminal microbiology, biotechnology, and ruminat nutrition: progress and problems. J. Anim. Sci., v.72, p.2992-3003, 1994. 